\title{
Assement of Severity of Community Acquired Pneumonia By CURB-65
}

Ahmed Talal Abdullah (MBChB , FICMS, MED) ${ }^{1}$ and Ismail Ibrahim Latif $(\mathrm{MBChB}, \mathrm{PhD}, \mathrm{HMD})^{2}$

\begin{abstract}
Background:Community-acquired pneumonia. is a disease in which individuals who have not recently been hospitalized develop an infection of the lungs, which can affect people at all ages. Pneumonia affecting about 2/1000 of the population per year.The initial assessment of the severity of community-acquired pneumonia is important for patient management. Severity assessment is an important early step in the management of patients presenting with community-acquired pneumonia. Various pneumonia-specific scores, generic sepsis scores and predictive biomarkers have been proposed as tools to aid clinicians in key management decisions.

Objective:The study was conducted to determine the efficacy of CURB-65 in the management of the Pneumonia.

Patients and Methods: 200 consecutive patients attending Baquba Teaching Hospital (108 female and 92 male) at a median age of 68 year, male(46\%) and female (54\%) between April 2017 and November 2018, diagnosed as CAP .

Results: CURB65 is useful in the evaluation of patients with CAP and determining the severity of the illness a clinical prediction rule suitable for use in busy casualty departments or admission units.

Conclusion: Iit include clinical features of prognostic importance, which were easily measurable at the time of initial assessment.

Keywords: Pneumonia, CURB-65, severity of CAP

Corresponding Author: dr.ahmadtalal@yahoo.com

Received: $9^{\text {th }}$ April 2019

Accepted: $25^{\text {th }}$ April 2019

\footnotetext{
${ }^{1}$ Baquba Teaching Hospital - Diyala - Iraq.

${ }^{2}$ College of Medicine - University of Diyala -Diyala- Iraq.
}

\section{Introduction}

In the assessment and management of community acquired pneumonia (CAP), severity of disease assessment is important, guiding management options such as the need for hospital or intensive care (ICU)

admission, suitability for discharge home, the extent of investigation, and choice and route of antimicrobial agent[1,2]. The Pneumonia Severity Index (PSI) developed by Fine et al in the USA provides a means of stratifying
\end{abstract}


groups of patients according to their risk of mortality and features in recently published North American guidelines[3,4].

Unfortunately it is difficult to use, requiring computation of a score based on 20 variables. In addition, it is best validated for assessing patients with a low mortality risk who may be suitable for home management rather than those with severe CAP at the time of hospital admission.

Other severity assessment tool proposed by the British Thoracic Society (BTS) and modified by Neill et al (mBTS)4 which relies on four easily measurable clinical features was developed mainly as a means of identifying patients with severe CAP at high risk of mortality. The presence of two or more of the following features - mental confusion, respiratory rate $30 / \mathrm{min}$, diastolic blood pressure $60 \mathrm{~mm} \mathrm{Hg}$, and blood urea $>7$ $\mathrm{mmol} / \mathrm{l}$ - predicted mortality with an overall sensitivity and specificity of about $80 \%$. (57) However, this tool also has limitations; by stratifying patients into only two groups (severe or non-severe) it does not identify patients at low risk of mortality who might be suitable for early hospital discharge or home management. The aim of this study was to determine the efficacy of CURB-65 score application to enable stratification of patients presenting to hospital with management of CAP.

\section{Patients and Methods}

200 consecutive patients attending Baquba Teaching Hospital (108 female (54\%) and 92 male (46\%)) at a median age of 68 year, male and femalebetween
April 2017 and November 2018, diagnosed as CAP.

\section{Diagnoses of CAP}

It is diagnosed by symptoms and examination and x-rays, and sometimes by examination of the sputum.

\section{Assessment of severity of CAP}

Severity assessment is recognized as an important step in the management of community-acquired pneumonia and determination of site and type of therapy.

\section{CURB65 score}

CURB-65 prediction tool was introduced in 2003 appears to be an advanced severity assessment tool CURB-65 is a clinical rule for predicting mortality in pneumonia. The CURB-65 includes:

Each risk factor scores one point, for a maximum score of 5:

1.Confusion : mental test score (MTS >8).

2.Urea $<7 \mathrm{mmol} / 1$

\section{Respiratory rate $<30 \mathrm{~b} / \mathrm{min}$}

4.Blood pressure systolic $>90$ or diastolic $>60$.

5.Age $<65$

Patients having one or more of the following were excluded from the study .Diagnosis of respiratory tract infection other than Pneumonia, patients whom initially diagnosed as CAP but there diagnosis was changed after admission to the hospital, patients whom lacked new infiltrate on the chest radiograph (atypical pneumonia), immunocompromised patients, malignancy, tuberculosis, patients had chronic respiratory disease, Age $<12$ years. And patients whom their radiological features did not improved 
during the 30 days period of follow up(slowly resolving pneumonia). The patients were divided into three groups (high, intermediate and low risk groups).

\section{Statistical analysis}

Statistical analysis performed with the statistical package for social sciences 21.0 and Microsoft Excel 2013. Data formulated as count and percentage. Fisher exact test was used to describe the association of these data. Numerical data were described as mean, standard deviation of mean. Independent sample t-test was used for comparison between two groups while analysis of variance was used for comparison among more than two groups. The lowest level of accepted statistical significant difference is bellow or equal to 0.05 .

\section{Results}

Figure(1) show Distribution of patients according to their gender. 92 male patients $(46 \%)$ and 108 female patients(54\%).

Regarding CURB65 score, (table 1) show the number of patients who have each CURB65 criteria. 56 patients(28\%) were having confusion, 104 patients $(52 \%)$ were have B.U>7mmol/1, 44 patients $(22 \%)$ were have R.R $>30 /$ minute, 12 patients $(6 \%)$ were have systolic B.P $<90 \mathrm{~mm} \mathrm{Hg}, 44$ patients (22\%) were have diastolic B.P $<60 \mathrm{~mm} \mathrm{Hg}$ and 132 patients $(66 \%)$ were their age $>65$ years.
Regarding CURB65 score Table(2) show distribution of patients according to CURB65 scores, 36 patients (18\%) have score (0), 44 patients $(22 \%)$ have score (1), 48 patients $(24 \%)$ have score $(2), 44$ patients (22\%) have score (3), 20 patients $(10 \%)$ have score (4) and 8 patients (4\%) have score (5).

Table(3) and table 4 showed that Of the 200 patients included in the study 80 patients (40\%) in the low risk group (CURB65=0-1) treated at home with oral antibiotics and followed up at outpatient clinic , 48 patients $(24 \%)$ in the intermediate risk group (CURB65=2) treated at hospital with short course I.V then oral antibiotics and 72 patients $(36 \%)$ in the high risk group (CURB65=3-5) Treated at hospital with I.V antibiotics with close monitoring and 12 patients admitted to the RCU.

Table(5) showed that the 30 day mortalities were $(0 \%)$ in the low risk group, $(16.5 \%)$ in the intermediate risk group and $(30 \%)$ in the high isk. The $\mathrm{p}$ value $<0,05$.

Table(6) the 30 day mortality regarding each CURB65 score. No patient died (0\%) who have scores( 0 and 1), 8 patients died (16.6\%) who have score(2), 12 patients died (27\%) who have score(3), 8 patients died (40\%) who have score(4) and 4 patient $(50 \%)$ who have score $(5)$. The $\mathrm{p}$ value $<0,05$. The over all mortality is (16\%). 


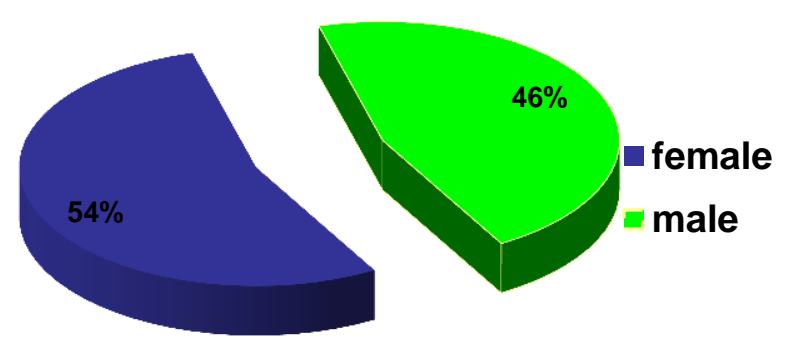

Figure(1): Distribution of patients according to their gender.

Table (1): Distribution of studied sample regarding their CURB65 criteria.

\begin{tabular}{|l|c|}
\hline \multicolumn{1}{|c|}{ CURB65 criteria } & Number of patients (\%) $\mathrm{n}=50$ \\
\hline \hline Confusion & $56(28 \%)$ \\
\hline \hline B.U $>7 \mathrm{mmol} / \mathrm{l}$ & $104(52 \%)$ \\
\hline \hline R.R $\geq 30 / \mathrm{minute}$ & $44(22 \%)$ \\
\hline \hline Systolic B.P $<90 \mathrm{mmHg}$ & $12(6 \%)$ \\
\hline \hline Diastolic B.P $<60 \mathrm{mmHg}$ & $44(22 \%)$ \\
\hline \hline Age $>65$ & $132(66 \%)$ \\
\hline
\end{tabular}

Table (2): Distribution of patients according to CURB65 score.

\begin{tabular}{|c|c|}
\hline "CURB65 score & Number of patients(\%) \\
\hline$\overline{00}$ & $\begin{array}{ll}36 & (18 \%)\end{array}$ \\
\hline$\overline{11}$ & $\begin{array}{ll}44 \quad(22 \%) \\
\end{array}$ \\
\hline 2 & 48 (24\%) \\
\hline 3 & $44 \quad(22 \%)$ \\
\hline 4 & $\begin{array}{ll}20 & (10 \%)\end{array}$ \\
\hline$\overline{5}$ & $\begin{array}{ll}8 & (4 \%)\end{array}$ \\
\hline Total & $200 \quad(100 \%)$ \\
\hline
\end{tabular}

Table (3): Distributions of patients in to the three CURB65 risk groups.

\begin{tabular}{|l|l|l||}
\hline CURB65 score & Risk group & $\begin{array}{l}\text { Number of } \\
\text { patients(\%) }\end{array}$ \\
\hline \hline$(0-1)$ & Low risk & $80(40 \%)$ \\
\hline \hline$(2)$ & Intermediate risk & $48(24 \%)$ \\
\hline \hline$(3-5)$ & High risk & $72(36 \%)$ \\
\hline
\end{tabular}


Table (4): The management guidelines according to severity.

\begin{tabular}{|l|c||c||}
\hline $\begin{array}{c}\text { CURB65 } \\
\text { score }\end{array}$ & $\begin{array}{c}\text { Number } \\
\text { of patients }\end{array}$ & \\
\hline \hline$(0-1)$ & 80 & Treated at home with oral antibiotics. \\
\hline \hline$(2)$ & 48 & Treated at hospital with short course I.V then oral antibiotics. \\
\hline \hline$(3-5)$ & 72 & Treated at hospital with I.V antibiotics with close monitoring . \\
\hline \hline
\end{tabular}

Table (5): The 30 day mortality according to risk group.

\begin{tabular}{|l|c||c|}
\hline \multicolumn{1}{|c|}{ CURB65 score } & Number of patients & 30-day mortality. (\%) \\
\hline \hline$(0-1)$ & 80 & $0(0 \%)$ \\
\hline \hline$(2)$ & 48 & $8(16.5 \%)$ \\
\hline \hline$(3-5)$ & $72^{\prime}$ & $24(30 \%)$ \\
\hline${ }^{p}=<0,05$
\end{tabular}

Table (6): The 30 day mortality regarding each CURB65.

\begin{tabular}{|c|c|c|}
\hline CEURB65 score & Number of patients & 30-day mortality*. (\%) \\
\hline$\overline{0}$ & 36 & (0\%) \\
\hline 1 & 44 & $(0 \%)$ \\
\hline 2 & 48 & $8(16.6 ; \%)$ \\
\hline 3 & 44 & $\begin{array}{ll}12 & (27 \%)\end{array}$ \\
\hline 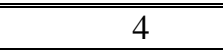 & 20 & $(40 \%)$ \\
\hline 5 & 8 & $(50 \%)$ \\
\hline
\end{tabular}

\section{Discussion}

In this study, there was slight difference in female to male ratio (1.2:1) and $66 \%$, were their age $>65$ this probably reflects the sex and age distribution in our population. Barlow, [8] found (35\%) of patients in the low risk group which is lower than thi study $(40 \%)$ and found (28\%) of patients in the intermediate risk group which is higher than this study $(24 \%)$ this is probably because many patients were partially treated at health care centers and out patient clinics before they were presented to us. In this Table(3) and (4), (36\%) of patients were in the high risk group this is comparable to Lim [24] who found it (35\%).

Lim [9] found (4\%) mortality in the low risk group which is higher than this study $(0 \%)$ this is probably because of limited number of patients in this study and 
difficulty of out patient follow up for this group.

Lim [9] found (33\%) mortality in CURB65 score 5 (which is $50 \%$ in our study) Table (5), this is probably because of greater facilities in ICU in which many patients acquiring this score were admitted and probably because of late presentation of our patients. In order to identify, synthesise and interpret the evidence relating to strategies to increase the proportion of low-risk patients with community-acquired pneumonia treated in the community, a systematic review of intervention studies conducted between 1981-2010. Articles were included if they compared strategies to increase outpatient care with usual care. They concluded that the proportion of patients treated as outpatients, hospital readmissions, mortality, health related quality of life, return to usual activities and patient satisfaction with care. The main analysis included six studies. The interventions in these studies were generally complex, but all involved the use of a severity score to identify low-risk patients. Overall, a significantly larger numbers of patients were treated in the community with these interventions (OR 2.31, 95\% CI 2.032.63). The interventions appear safe, with no significant differences in mortality (OR 0.83 , 95\% CI 0.59-1.17), hospital readmissions (OR 1.08, 95\% CI 0.82-1.42) or patient satisfaction with care (OR 1.21, 95\% CI 0.97-1.49) between the intervention and control groups. There was insufficient data regarding quality of life or return to usual activities. All studies had significant limitations. The available evidence suggests that interventions to increase the proportion of patients treated in the community are safe, effective and acceptable to patients [10].

\section{Conclusions}

1.CURB65 is useful in the evaluation of patients with CAP and determining the severity of the illness a clinical prediction rule suitable for use in busy casualty departments or admission units, it include clinical features of prognostic importance, which were easily measurable at the time of initial assessment.

2.The low mortality in low risk group (CURB65 score 0-1) and the increasing mortality in the intermediate and then high risk groups indicate that CURB65 effectively stratified patients regarding the site of medical care , type and rout of administration of treatment and predicting mortality.

\section{References}

[1]Bartlett JG, Dowell SF, Mandell LA. Practice guidelines for the management of community-acquired pneumonia in adults. Infectious Diseases Society of America. Clin Infect Dis 2000;31:347-82.

[2]Mandell LA, Marrie TJ, Grossman RF, Canadian guidelines for the initial management of community-acquired pneumonia: an evidence-based update by the Canadian Infectious Diseases Society and the Canadian Thoracic Society. The Canadian Community- Acquired Pneumonia Working Group. Clin Infect Dis 2000;31:383-421.

[3]Fine MJ, Auble TE, Yealy DM. A prediction rule to identify low-risk patients 
with community- acquired pneumonia. $\mathrm{N}$ Engl J Med 1997;336:243-50.

[4]Neill AM, Martin IR, Weir R. Community acquired pneumonia: aetiology and usefulness of severity criteria on admission. Thorax 1996;51:1010-6.

[5]British Thoracic Society and Public Health Laboratory Service . Communityacquired pneumonia in adults in British hospitals in 1982-1983: a survey of aetiology, mortality, prognostic factors and outcome. Q J Med 1987;62:195-220.

[6] Lim WS, Macfarlane JT, Boswell TC, et al. Study of community acquired pneumonia aetiology (SCAPA) in adults admitted to hospital: implications for management guidelines. Thorax 2001;56:296-301.

[7]Lim WS, Lewis S, Macfarlane JT. Severity prediction rules in community acquired pneumonia: a validation study. Thorax 2000;55:219-23.

[8]Gavin Barlow, Dilip Nathwani,Peter Davey.theCURB65 pneumonia severity score. Thorax 2007;62:253-259.

[9]W S Lim, M van der Eerden, R Laing Defining community acquired pneumonia severity on presentation to hospital. Thorax 2003;58:377-382.

[10]Chalmers JD, Akram AR, Hill AT. Increasing outpatient treatment of mild community-acquired pneumonia: systematic review and meta-analysis. Eur Respir J 2011; $37: 858$. 